\title{
INTERLOCUÇÕES ENTRE A DECOLONIALIDADE E A FORMAÇÃO DE PROFESSORES: UM CENÁRIO EM PERSPECTIVA
}

\section{DÉBORA SANTOS DE ANDRADE DUTRA}

\author{
Instituto Federal do Espírito Santo
}

E-mail: deborasad@ifes.edu.br

\section{BRUNO ANDRADE PINTO MONTEIRO}

\author{
Universidade Federal do Rio de Janeiro \\ E-mail: bpmonteiro@gmail.com
}

\begin{abstract}
RESUMO
Neste trabalho apresentamos uma revisão de literatura a partir de artigos em periódicos que tratam da formação de professores em diálogo com a decolonialidade, a fim de investigar o contexto das pesquisas realizadas. Observamos que os trabalhos possuem um amplo espectro de discussões, num movimento de resistência e reexistência para transformar as práticas pedagógicas. Envolvem sujeitos (professores, alunos, comunidades) em diversos contextos: educação indígena, relações étnicoraciais, questões de gênero e sexualidade, refugiados e outros. Os autores mais citados são Catherine Walsh, Walter Mignolo, Anibal Quijano, Paulo Freire, Vera Candau. A escola é vista como um espaço onde se reproduz colonialidades, por isso, destacamos a importância de ampliar o diálogo com professores, para que, além do conhecimento específico, discutam problemas sociais, políticos, econômicos, ambientais, numa perspectiva decolonial. Identificamos poucos trabalhos no âmbito da educação em ciências e matemática.
\end{abstract}

\section{PALAVRAS-ChAVE:}

Decolonialidade; Formação de Professores; Revisão de literatura.

\section{INTERLOCUTIONS BETWEEN DECOLONIALITY AND TEACHER TRAINING: A SCENE IN PERSPECTIVE}

\begin{abstract}
In this paper, we present a literature review based on articles in journals dealing with teacher education in dialogue with decoloniality, in order to investigate the context of the research carried out. We observe that the works have a wide spectrum of discussions, in a movement of resistance and re-existence to transform pedagogical practices. They involve subjects (teachers, students, communities) in different contexts: indigenous education, ethnic-racial relations, gender and sexuality issues, refugees and others. The most cited authors are Catherine Walsh, Walter Mignolo, Anibal Quijano, Paulo Freire, and Vera Candau. The school is a space where colonialities are reproduced, therefore, the importance of expanding the dialogue with teachers is perceived, so that, in addition to specific knowledge, they meed to discuss social, political, economic, environmental, in a decolonial perspective. There are few works in the field of science and mathematics education.
\end{abstract}


KEYWORDS:

Decoloniality; Teacher Trainin; Teacher education; Literature Review.

\section{INTRODUÇÃO}

Numa sociedade em mudanças, diversos desafios são apresentados aos professores cotidianamente. Muitas responsabilidades thes são requeridas e sobre o seu trabalho incide questões sociais, políticas, econômicas e ambientais que se refletem nas relações pedagógicas, exigindo novos modos de ensinar e aprender. Dessa forma, faz-se importante dialogar com professores, a partir de um olhar que aponte para a busca de outras maneiras de pensar e fazer, levando em consideração essas questões que, muitas vezes, passam despercebidas durante nossas ações pedagógicas. As discussões que permeiam o pensamento decolonial e decolonialidade nos trazem alternativas para ampliar esse olhar sobre a sociedade, sobre a formação e sobre a escola.

Nesse sentido, para compreender a decolonialidade ${ }^{1}$ faz-se necessário entender como se deu o processo de colonialidade que, de acordo com Quijano (2010), é um dos elementos que constitui o padrão de poder capitalista no mundo: "Sustenta-se na imposição de uma classificação racial/étnica da população do mundo como pedra angular do referido padrão de poder e opera em cada um dos planos, meios e dimensões, materiais e subjetivos, da existência social quotidiana e da escala societal" (QUIJANO, 2010, p.84). Segundo o autor, a colonialidade distingue-se do colonialismo ainda que ligado a ele, o qual alude a dominação de territórios a uma estrutura de "dominação/exploração onde o controle da autoridade política, dos recursos de produção e do trabalho de uma população determinada domina outra de diferente

\footnotetext{
${ }^{1}$ Utilizamos o termo 'decolonial' e "decolonialidade" conforme apontado por Catherine Walsh. A autora considerou a eliminação do "s" para distinguir do significado de descolonizar em seu sentido de 'desfazer' algo e salienta que intenção do movimento decolonial não é desfazer o colonial ou superar o momento colonial em favor do pós-colonial, mas sim provocar um posicionamento contínuo e cotidiano de transgressão e insurgência.
} 
identidade e cujas sedes centrais estão, além disso, localizadas noutra jurisdição territorial" (QUIJANO, 2010, p.84).

Tal padrão de dominação criou relações hierárquicas e dicotômicas entre os dominadores e dominados numa relação exploração, violências e apagamentos de culturas, conhecimentos e subjetividades dos grupos dominados. A colonialidade se apresenta em suas diversas formas como a colonialidade do poder, a colonialidade do saber, a colonialidade do ser e a colonialidade cosmogônica ou da natureza (QUIJANO, 2010; MIGNOLO, 2008; WALSH, 2009). Dessa forma, a independência territorial não extingue os graves efeitos da colonialidade, impregnados nas relações cotidianas que mantém relações hierárquicas de poder e produzem desigualdades, racismo, sexismo e injustiças sociais.

A decolonialidade propõe o rompimento das estruturas que mantêm a colonialidade, isto é, romper com a via única de conhecimento e existência por uma existência plural. Assim é necessária uma reorientação epistêmica que faça emergir saberes, ontologias, cosmovisões e se contraponha ao poder hegemônico a fim de decolonizar em todas as dimensões do poder, do saber, do ser e da natureza. Dessa forma, "Descolonial implica pensar a partir das línguas e das categorias de pensamento não incluídas nos fundamentos dos pensamentos ocidentais" (MIGNOLO, 2008, p. 305). Autores concordam que a decolonialidade requer a prática, para além das teorias. Mignolo (2008) afirma que além do pensamento descolonial, é necessário o fazer descolonial. Ballestrin (2013, p.105) considera que a decolonialidade é o "movimento de resistência teórico e prático, político e epistemológico, à lógica da modernidade/colonialidade". Nesse sentido Walsh (2017), defende que a busca pela decolonialidade sugere uma forma de vida, em que viver o decolonial é refletir na prática cotidiana a busca de novas formas de (re)existências, ou seja, o fazer diferente entre gretas e fissuras dentro da sociedade. Segundo Mignolo (2008), num contexto decolonial é necessário aprender a desaprender, para reaprender a pensar a e se 
conectar com o mundo, o que não significa abandonar conhecimentos construídos ou formar 'novos resumos universais', mas aprender a pensar fora da estrutura na qual fomos treinados. Dentro desse contexto, a escola é uma estrutura que reproduz discursos e práticas hegemônicas que suprime as diversas formas de existência. Pensar a formação de professores num diálogo com as discussões decoloniais pode trazer possibilidades para uma educação plural que reconheça outras formas de ser e pensar, assim, possibilitar a ressignificação de experiências, combater as desigualdades e contribuir para a formação de uma sociedade humanizada.

Nesse sentido, percebemos que ainda há poucas pesquisas com este enfoque no âmbito de formação de professores, mas constata-se um crescente interesse pelo tema. O objetivo desse trabalho é mapear artigos que tratam da formação de professores da perspectiva da decolonialidade e investigar como o tema tem sido discutido e abordado na formação de professores Dessa forma, o direcionamento desse trabalho de revisão parte das seguintes questões: Como a formação de professores tem sido discutida no âmbito de artigos que tem a decolonialidade como enfoque? Como o tema da decolonialidade é discutido e/ou abordado no âmbito dessas formações? Para isso foi sistematizado um roteiro para a realização da revisão de literatura.

\section{Percurso Metodológico}

Para a revisão de literatura, utilizamos como referência o trabalho de Ramos (et al, 2014) que sugere um caminho para auxiliar a realização da revisão de literatura e garantir que a análise possa trazer resultados. Nesse sentido, orientam definir os critérios e métodos para selecionar o material bibliográfico e objeto da revisão. A revisão reúne uma pesquisa sobre a questão a ser analisada e os procedimentos para analisar e sintetizar os resultados de pesquisa no âmbito do estudo, a fim de obter resultado objetivo (RAMOS et al, 2014). Os autores sugerem etapas que devem ser 
destacados no processo da pesquisa, a fim de que possa ser utilizado por outros pesquisadores: os objetivos, as equações de pesquisa, o âmbito; os critérios de inclusão; os critérios de exclusão; os critérios de validade metodológica; os resultados; o tratamento dos dados (RAMOS et al, 2014). Esses critérios foram adaptados e utilizados nesse trabalho. A opção inicial do estudo foi buscar pesquisas que discutissem a formação de professores na perspectiva da decolonialidade no âmbito do ensino de matemática. No entanto, não houve retorno de resultado significativo na busca. Dessa forma, optamos por investigar trabalhos que, de uma forma geral, trazem discussões sobre a formação de professores no âmbito da decolonialidade ${ }^{2}$. Assim, definimos e discutimos as etapas do processo da revisão como sugerido por Ramos et al. (2014).

\subsection{Procedimentos PARA ReVISÃo NoS ARTIGOS}

Foram adotados para a revisão dos artigos os seguintes procedimentos: a) Objetivo: Identificar estudos desenvolvidos no Brasil e no mundo que tratam da formação de professores na perspectiva da decolonialidade em todos os níveis de ensino; b) Âmbito da pesquisa: A busca pelos artigos foi realizada no portal Periódicos Capes por Acesso Proxy da UFRJ, que disponibiliza o acesso remoto integrado a serviços de informação científica e tecnológica internacional à comunidade acadêmica da universidade; c)Equações da pesquisa: Após alguns testes, foram definidos os termos de busca que possibilitassem o retorno do maior número de artigos contendo os termos "decolonial" (e seus derivados) e "formação de professores. Assim, em abril de 2020 efetuamos as buscas 1 e 2 e posteriormente a busca 3, sendo concluído o

\footnotetext{
${ }^{2}$ O estudo completo da revisão Sistemática da Literatura foi constituído pela análise de pesquisas a partir de buscas em dois cenários: a) artigos na Plataforma de Periódicos da Capes; b) Teses e Dissertações no Catálogo de Teses e Dissertações da Capes. Nesse artigo, apresentamos os resultados apenas do cenário do item a). As duas análises se complementam e são partes integrantes de uma pesquisa de doutorado em andamento que trata da 'decolonialidade na formação de professores que ensinam matemática.
} 
levantamento em julho de 2020, utilizando-se operadores boleanos ${ }^{3}$, de truncamento

e os termos de busca que consideramos apropriados naquele momento (Quadro 1):

Quadro 1: Termos utilizados nas buscas. Fonte: Os autores.

\begin{tabular}{|l|l|}
\hline Termos de Busca & Total de artigos \\
\hline 1 - Decolonial* And "formação de professores" & 9 (Títulos em português e espanhol) \\
\hline 2 - Decolonial* And "Teacher training" & 50 (Títulos em inglês e espanhol) \\
\hline 3 - Decolonial* And "Formação docente" & 6 (Títulos em português e espanhol) \\
\hline
\end{tabular}

Foram disponibilizados 65 títulos para análise que continham os termos indicados na busca. Não houve recorte temporal para a busca.

Além dos procedimentos citados anteriormente, também foram utilizados: d) Critérios de inclusão e critérios de exclusão: Foi realizada uma leitura nos títulos, resumos e palavras-chave, a fim de identificar artigos que atendessem a os requisitos e a os objetivos da pesquisa. Além disso, foram observados artigos em comum às duas buscas. Após a leitura consideramos que 26 artigos articulam a decolonialidade à formação de professores, dos quais, dois artigos foram acessados completamente, restando 24 textos para análise. Numa leitura mais criteriosa dos artigos, observamos que seis textos não tinham o enfoque requerido para a pesquisa e foram excluídos do elenco de artigos a serem investigados. Ainda foi incluído um artigo recente sobre o tema de interesse, o qual foi encontrado após a primeira busca, totalizando 19 artigos. Após algumas inquietações, fizemos a terceira busca, que retornou 6 artigos publicados entre 2010 e 2019, dos quais um já constava em busca anterior e dois estavam de acordo com o critério estabelecido. Por fim, 21 artigos foram utilizados nessa análise. Em síntese, foram incluídos os artigos que articulam a formação de professores e a decolonialidade e estejam completos. Foram excluídos artigos que não

3 Foram utilizados operadores: AND, " " $\mathrm{e}^{*}$.

a) O operador " " foi utilizado para buscar termos compostos, na forma exata.

b) Operador de Truncamento: O simbolo * foi utilizado para obter termos derivados a partir do sufixo. Assim, decolonial* dará retorno dos termos: decolonialidade, decoloniality, decolonial, decolonialismo e etc. Observamos também o retorno de textos com termos: descolonizante, descolonial e outros similares. 
tiveram o tema formação de professores como objetivo, ainda que de forma secundária. e) Critério de validade metodológica: O processo de busca foi repetido várias vezes não sendo observadas variações no retorno dos artigos. f) Resultados: Serão apresentados no decorrer deste texto. g) Tratamento dos dados: Os dados selecionados foram analisados criticamente, distribuídos em conjuntos de abordagens.

\section{CenÁRIos dAs PROduções dos ARTigos}

\subsection{Panorama da Publicação dos Artigos}

Quanto aos números e locais de artigos publicados: Foi possível observar que há evolução na quantidade de pesquisas que articulam a formação de professores e a perspectiva decolonial. No entanto esse movimento é recente, mostrando um crescimento significativo a partir de 2017, conforme a Figura 1.

Figura 1: Quantidade de artigos publicados por ano. Fonte: Os autores.

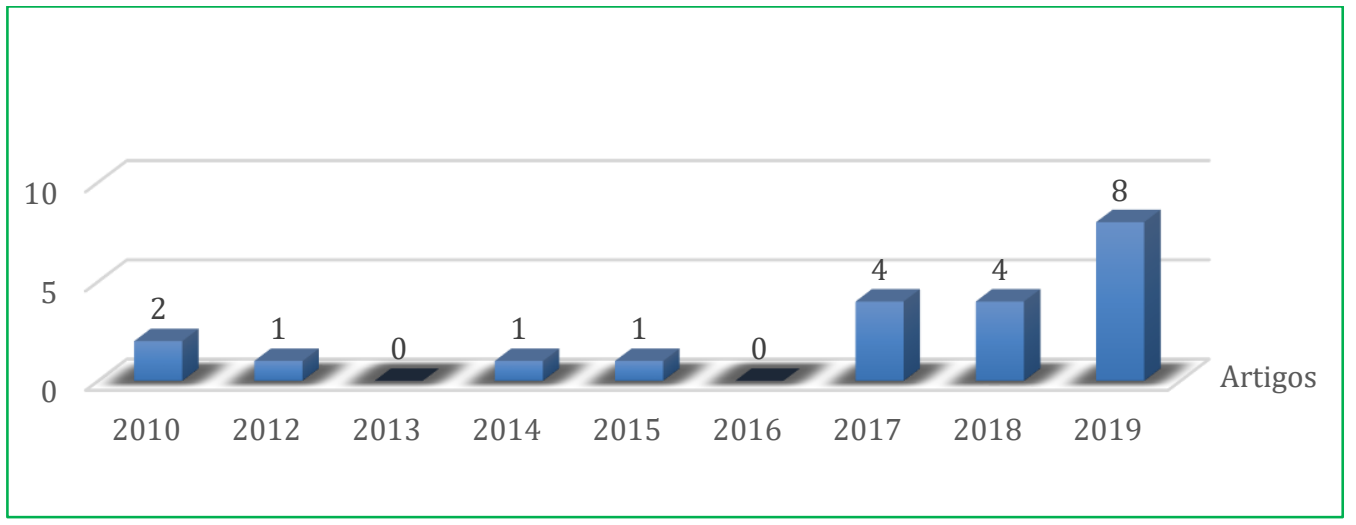

Os trabalhos analisados foram desenvolvidos, em sua maioria, na América Latina em um total de 12 artigos, os quais ficaram assim distribuídos: Argentina - 1; Austrália -1; Brasil - 9; Canadá - 1; Colômbia - 3; Equador - 1; EUA - 3; EUA/Quênia -1; Países Baixos - 1, conforme a Figura 2. 
Figura 2: Quantidade de artigos por países das instituições de origem dos pesquisadores. Fonte: Os autores.

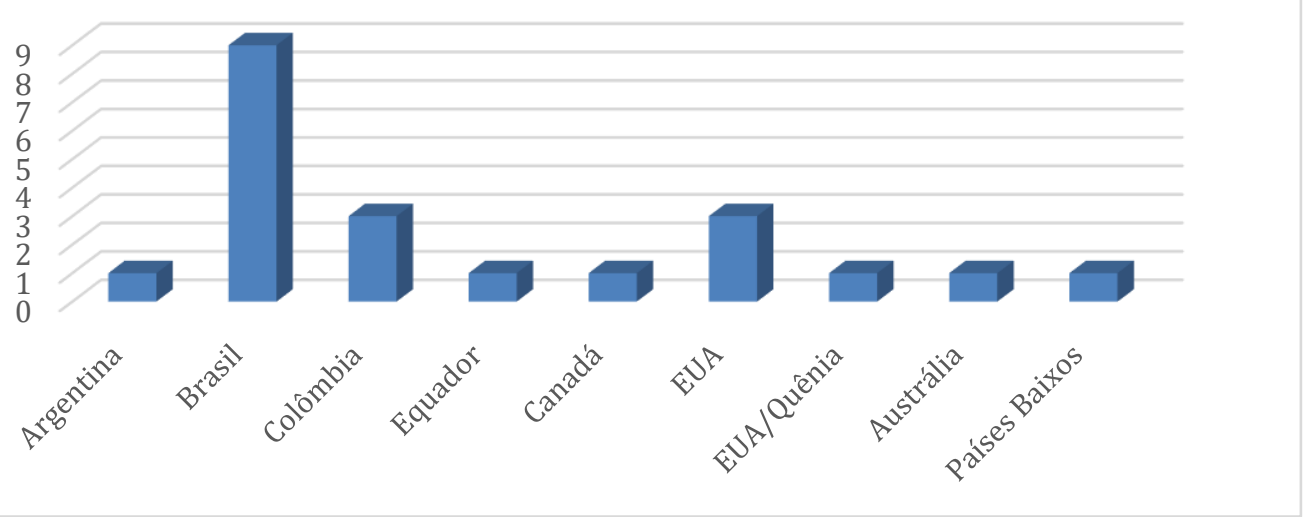

Observamos que mesmo essa discussão sendo recente no Brasil, em nossa busca, o maior número de artigos escolhidos para essa revisão é de autores vinculados a universidades e outras instituições brasileiras.

Quanto aos autores referenciados nos artigos: Os pesquisadores latinoamericanos que compõem o grupo Modernidade/Colonialidade (M/C), formado nos anos 1990 por intelectuais de diversas instituições que se comprometeram a deslocar o pensamento colonial - 'giro decolonial'- (BALLESTRIN, 2013), é o nosso ponto de partida para localizar os autores que discutem teorias e pensamento decolonial. Entre os autores podemos citar: Catherine Walsh, Walter Mignolo, Aníbal Quijano, Boaventura Sousa Santos, Edgardo Lander, Arthuro Escobar, Ramon Grosfóguel, Immanuell Wallerstein e outros (BALLESTRIN, 2013). Nos artigos externos à AméricaLatina, as referências foram obtidas a partir da indicação dos autores no texto e do referencial. Observamos que há outros pesquisdores que também são referências, por movimentarem-se no sentido da resistência contra hegemônica, como por exemplo, Paulo Freire. Dos dados, os autores mais citados para referenciar e/ou discutir o pensamento decolonial destacados foram: Catherine Walsh, Paulo Freire, Walter Mignolo, Vera Candau, Anibal Quijano, Boaventura Souza Santos e Luiz Fernando Oliveira, conforme a Figura 3. 
Figura 3: Frequência dos autores apontados como decoloniais referenciados nos artigos - criado com o software Nvivo. Fonte: Os autores.

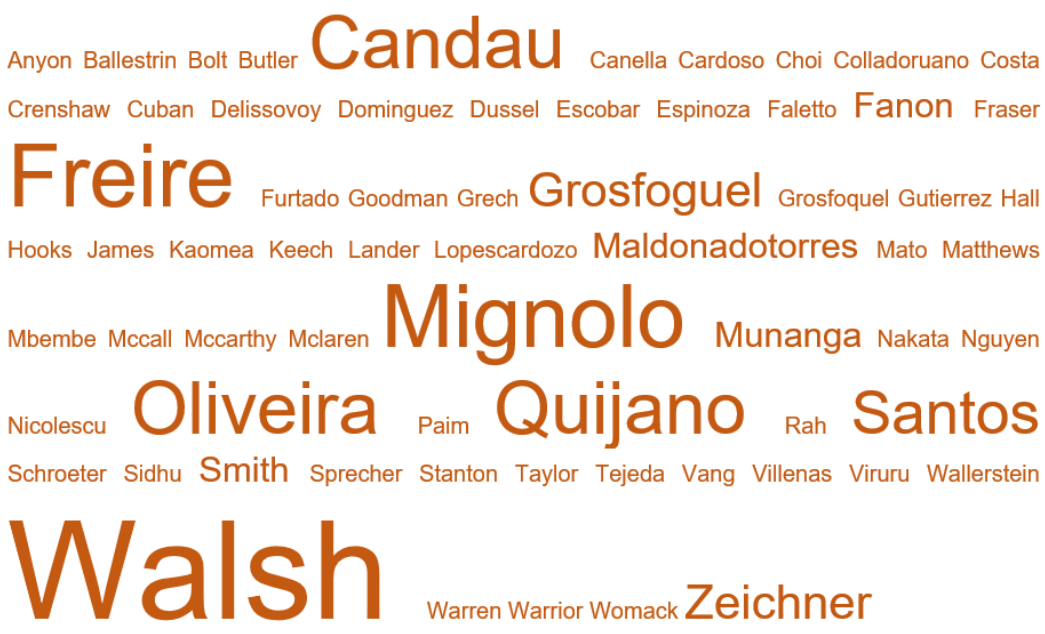

É possível destacar que os intelectuais do pensamento decolonial latinoamericano se sobressaem, o que é compreensível visto que 14 dos 21 artigos são de autores vinculados a instituições latino-americanas, o que demonstra a força da América Latina desse movimento. Catherine Walsh é a autora mais referenciada, citada na maioria dos artigos.

Quanto às palavras-chave: As palavras-chave indicadas pelos autores sugerem termos importantes para o campo da decolonialidade e a formação de professores nessa perspectiva. Em duas publicações, não houve indicação de palavras-chave e, nesse caso, foram utilizadas as palavras principais indicadas pelo autor no título. 
Figura 4: Frequência das palavras que compõem os termos chave dos artigos- Quadro criado com o software Nvivo. Fonte: Os autores.

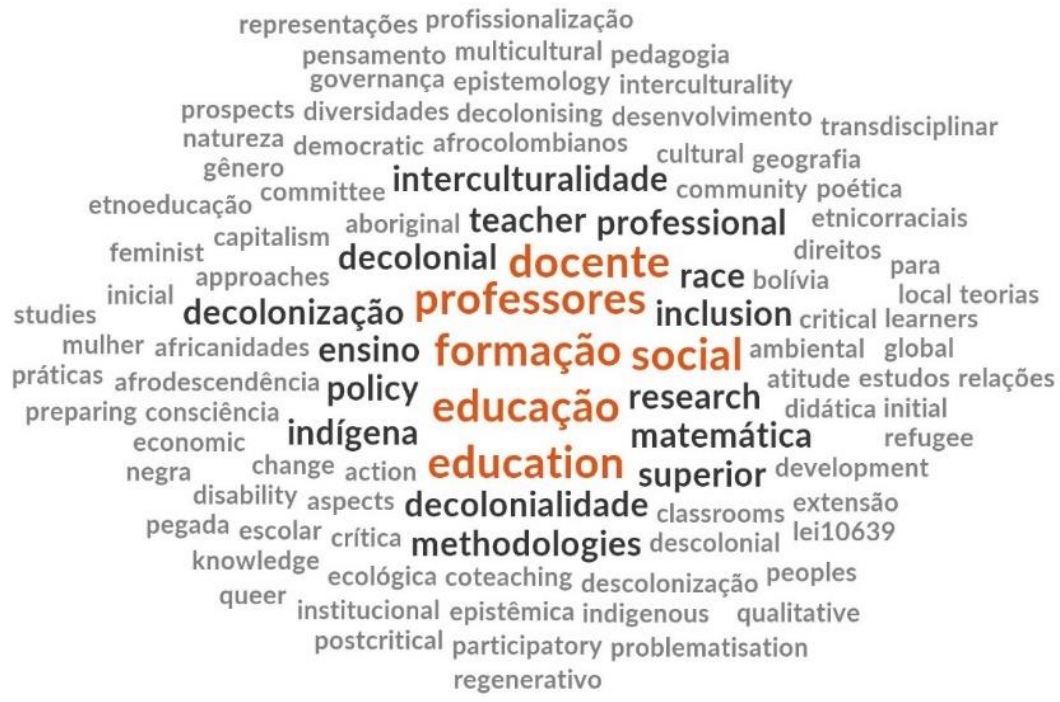

O conjunto de palavras que compõem a Figura 4 abrange a formação de professores e a decolonialidade (e outros termos derivados que são objeto dessa revisão) e acrescenta outros termos que estão atreladas ao tema como: a interculturalidade crítica, epistemologias, políticas, multicultural, afrodescendência, entre outras. Observamos que os artigos tratam da formação de professores em contextos diversos e, nessas discussões, estão envolvidas: a educação indígena, educação para as relações étnico raciais, educação e gênero, teoria Queer na formação, educação inclusiva entre outras. Os sujeitos com relações assimétricas apontados nos artigos envolvem grupos diversos como: mulheres, afro-brasileiros, afro-colombianos, indígenas (brasileiros, bolivianos e australianos), pessoas com deficiência, comunidades periféricas, refugiados entre outros. Essas discussões levantam a necessidade da formação de professores para a diversidade em mundo globalizado, para o qual os professores precisam estar preparados, numa ação de resistência ao sistema hegemônico, independentemente do conteúdo disciplinar que lecionam. Essas relações estão de acordo com as discussões dos autores sobre a 
colonialidade, decolonialidade e resistência (QUIJANO, 2010; WALSH, 2015,2017; MIGNOLO, 2008; FREIRE, 1988; SANTOS, 2004 e outros).

\section{DISCUSSÃO DOS TRABALHOS}

A partir da leitura dos textos percebemos similaridades de lutas, de sujeitos, de abordagens e propostas que nos levaram a construir grupos de artigos. As propostas perpassam por práticas pedagógicas decoloniais, relatos de resistência e reexistência, lutas por justiça social e desobediências epistêmicas, dialogando com autores que discutem os movimentos decoloniais. Alguns trabalhos poderiam ser agregados em mais de um grupo, mas escolhemos agrupá-los da forma exposta para facilitar a discussão.

\subsection{EDUCAÇÃO INDÍGENA}

A formação de professores para a educação escolar indígena e com professores e a escola indígena foi uma preocupação importante destacada nos artigos, por percebemos a necessidade de: formação professores indígenas e não indígenas, respeitar os saberes dos povos indígenas e integrá-los às abordagens e, ainda, verificar contribuições da pesquisa com professores indígenas para a formação dos professores pesquisadores (Quadro 2).

Quadro 2: Dados dos artigos agrupados em 'Educação Indígena. Fonte: Os autores.

\begin{tabular}{|c|c|c|c|c|}
\hline \multicolumn{5}{|c|}{ Educação indígena } \\
\hline Cód. & Título & Autores & Periódico & Ano \\
\hline A1 & $\begin{array}{l}\text { Action Research and } \\
\text { intercultural dialogue: An } \\
\text { experience with Brazilian } \\
\text { Indians }\end{array}$ & $\begin{array}{l}\text { Ruth Pavan; Maria Cristina } \\
\text { Lima Paniago; José Licinio } \\
\text { Backes } \\
\text { Universidade Católica Dom } \\
\text { Bosco (UCDB) - Brasil }\end{array}$ & $\begin{array}{l}\text { International } \\
\text { Journal of } \\
\text { Action } \\
\text { Research }\end{array}$ & 2015 \\
\hline A2 & $\begin{array}{l}\text { Extensão universitária: } \\
\text { contribuições de professores } \\
\text { guarani para a formação } \\
\text { inicial de professores de } \\
\text { matemática. }\end{array}$ & $\begin{array}{l}\text { Gabriela Dos Santos Barbosa } \\
\text { Universidade do Estado do Rio } \\
\text { de Janeiro - Brasil }\end{array}$ & $\begin{array}{l}\text { Espaço } \\
\text { Pedagógico }\end{array}$ & 2018 \\
\hline
\end{tabular}




\begin{tabular}{|c|c|c|c|c|}
\hline \multicolumn{2}{|c|}{ 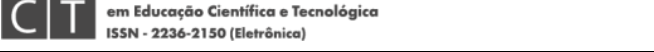 } & \multicolumn{3}{|c|}{ Revista Eletrônica DECT, Vitória (ES), v. 10, edição especial dinter, p. 94-128, 2020} \\
\hline A3 & $\begin{array}{l}\text { Interculturalidade Crítica, } \\
\text { Transdisciplinaridade e } \\
\text { Decolonialidade na Formação } \\
\text { de Professores Indígenas do } \\
\text { Povo Berò Biawa } \\
\text { Mahadu/Javaé: Análise de } \\
\text { Práticas Pedagógicas } \\
\text { Contextualizadas em um } \\
\text { Curso de Educação } \\
\text { Intercultural Indígena. }\end{array}$ & $\begin{array}{l}\text { Elias Nazareno; Sônia Maria } \\
\text { Magalhães; Marco Urzeda } \\
\text { Freitas } \\
\text { Universidade Federal de Goiás } \\
\text { - Brasil }\end{array}$ & $\begin{array}{l}\text { Fronteiras: } \\
\text { Journal of } \\
\text { Social, } \\
\text { Technological } \\
\text { and } \\
\text { Environmental } \\
\text { Science }\end{array}$ & 2019 \\
\hline A4 & $\begin{array}{l}\text { Learning about knowledge: } \\
\text { threshold concepts for } \\
\text { Indigenous studies in } \\
\text { education }\end{array}$ & $\begin{array}{l}\text { Nikki Moodie } \\
\text { University of Melbourne - } \\
\text { Austrália }\end{array}$ & $\begin{array}{l}\text { The Australian } \\
\text { Educational } \\
\text { Researcher }\end{array}$ & 2019 \\
\hline
\end{tabular}

No artigo $\mathrm{A} 1$, os autores relatam como suas pesquisas realizadas com grupos indígenas contribuíram para a própria formação tanto como pesquisadores quanto como educadores, tendo seus estudos alinhados à pesquisa-ação como metodologia, para a qual consideram a sala de aula um ambiente apropriado e preferencial para esse tipo de pesquisa. A partir dessas discussões e da interculturalidade crítica, os autores destacam três eixos do aprendizado que consideraram ter marcado suas identidades de educadores/pesquisadores: a) a declaração de identidade produz/fortalece a luta contra a desigualdade econômica; b) é sempre necessário colocar em questão as teorias e construir um novo significado; c) a comunidade indígena étnica resiste ao avanço da sociedade individualista neoliberal (PAVAN et al., 2015).

No artigo A2 os autores analisaram contribuições de um projeto de extensão de formação continuada de professores indígenas Guaranis, para o ensino de matemática. Pautado na Pedagogia Decolonial, Barbosa (2018) verificou impactos das interações entre os professores indígenas e suas culturas sobre os estudantes de licenciatura e sua formação. Os licenciandos puderam rever suas concepções sobre a matemática e da educação matemática, observar de forma crítica os saberes da formação e saberes curriculares propostos pela universidade diante da relativização 
de outros saberes matemáticos e pedagógicos, como os do Povo Guarani e reconhecer as funções políticas das ações de um professor (BARBOSA, 2018). A autora destaca que os licenciandos e os professores Guarani contribuíram mutuamente para a formação uns dos outros, favorecendo a não-hierarquização de saberes e a construção de novos saberes docentes.

O estudo de A3 busca, a partir de reflexões e novas práticas pedagógicas contextualizadas, perceber como emergem e se afirmam os conhecimentos indígenas por alunos do povo Jaevé, num Curso Educação Intercultural Indígena (CEII) cujo objetivo foi a formação de professores indígenas que atuam nos seus territórios nas regiões Araguaia-Tocantins e Xingu, em escolas indígenas, abrangendo 25 povos. Os futuros professores foram incentivados a incluir, em sua prática pedagógica, os conhecimentos próprios do seu povo. A pesquisa apontou que a interculturalidade crítica possibilitou diminuir o abismo entre os conhecimentos indígenas e os ocidentais, permitindo os professores e povos indígenas a se posicionarem em relação ao que consideram importante dentro e fora do ambiente escolar. Perceberam que os professores consideram a escola como um ambiente de resistência e reafirmação dos saberes indígenas. Na conclusão, constataram que as práticas pedagógicas dos pesquisados "rompem com o projeto unidimensional da modernidade colonial, funcionando como ferramentas políticas de reconhecimento, afirmação das diferenças e, portanto, de decolonialidade do saber" (NAZARENO et al., 2019, p. 505).

O artigo A4 tratou da educação indígena no contexto australiano, discutiu os "conceitos de limiar" (threshold concepts) e propôs a sua utilização no âmbito dos estudos indígenas na formação de professores. Moodie (2019) destaca que as pesquisas sobre ensino e aprendizagem indígena se concentram no currículo e pedagogias, mas não indicam quais conhecimentos prévios se devem ter sobre questões indígenas, compondo uma lacuna na formação de professores que não se sentem preparados para trabalhar com a educação indígena nem com o conteúdo 
curricular indígena. Moodie (2019) sugere cinco conceitos limiares para a educação indígena na formação de professores: raça, país/lugar, relacionalidade ou interconexão e reciprocidade, política e problemas de representatividade e igualdade epistêmica. A autora destaca que os conceitos limiares podem fornecer outra estrutura para o desenvolvimento de conhecimento de conteúdo sobre questões indígenas em contextos da formação profissional, que permitirão novas maneiras de pensar (MOODIE, 2019).

\subsection{RESISTÊNCIA, PolítICAS E JUSTIÇA SOCIAL}

A resistência é um atributo inerente às lutas e a todas as propostas decoloniais. Os dez artigos agrupados neste item tratam de questões nas quais uma educação baseada numa proposta decolonial possibilite uma luta que possa se transformar em políticas de resistência. No Quadro 3, apresentamos os artigos que discutem essas questões na formação de professores para transformação de realidades sociais em diversos contextos.

Quadro 3: Dados dos artigos agrupados em 'Resistência, políticas e justiça social'. Fonte: Os autores.

\begin{tabular}{|c|l|l|l|l|}
\hline \multicolumn{5}{|c|}{ Desobediência epistêmica, resistências, políticas e justiça social } \\
\hline Cód & \multicolumn{1}{|c|}{ Título/ Autores(as) } & \multicolumn{1}{|c|}{ Autores (as) } & \multicolumn{1}{c|}{ Periódico } & Ano \\
\hline A5 & $\begin{array}{l}\text { Una reescritura } \\
\text { contrahegemónica de la } \\
\text { formación de docentes }\end{array}$ & $\begin{array}{l}\text { Jorge Huergo } \\
\text { Kevin Morawicki }\end{array}$ & $\begin{array}{l}\text { Nómadas } \\
\text { (Colombia) }\end{array}$ & 2010 \\
\hline \multirow{2}{*}{ A6 } & $\begin{array}{l}\text { Transforming pre-service } \\
\text { teacher education in Bolivia: } \\
\text { from indigenous denial to } \\
\text { decolonisation? }\end{array}$ & $\begin{array}{l}\text { Mieke T.A. Lopes Cardozo } \\
\text { University of Amsterdam - } \\
\text { Países Baixos }\end{array}$ & $\begin{array}{l}\text { Compare: A jornal } \\
\text { of Comparative and } \\
\text { International } \\
\text { Education: } \\
\text { Indigenous } \\
\text { Knowledges and } \\
\text { Education }\end{array}$ & 2012 \\
\hline A7 & $\begin{array}{l}\text { Processos e práticas } \\
\text { decoloniais na formação de } \\
\text { professores }\end{array}$ & $\begin{array}{l}\text { Alessandra Fontes Carvalho } \\
\text { Da Rocha } \\
\text { Universidade Federal do Rio } \\
\text { de Janeiro - Brasil }\end{array}$ & $\begin{array}{l}\text { Revista Latino } \\
\text { Americana de } \\
\text { Estudos em Cultura } \\
\text { e Sociedade }\end{array}$ & 2017 \\
& \multicolumn{3}{|l}{} \\
\hline
\end{tabular}




\begin{tabular}{|c|c|c|c|c|}
\hline A8 & $\begin{array}{l}\text { Comparative International } \\
\text { Approaches to Better } \\
\text { Understanding and } \\
\text { Supporting Refugee } \\
\text { Learners }\end{array}$ & $\begin{array}{l}\text { Julie Ficarra } \\
\text { Syracuse University - EUA }\end{array}$ & $\begin{array}{l}\text { Issues in Teacher } \\
\text { Education }\end{array}$ & 2017 \\
\hline A9 & $\begin{array}{l}\text { Preparing Teacher- } \\
\text { Researchers for Local- } \\
\text { Global, Multicultural } \\
\text { Classrooms: Prospects for } \\
\text { Postcritical and Feminist } \\
\text { Qualitative Methodologies. }\end{array}$ & $\begin{array}{l}\text { Katharine Sprecher } \\
\text { University of Tennessee - } \\
\text { EUA }\end{array}$ & $\begin{array}{l}\text { The Journal of } \\
\text { Culture and } \\
\text { Education. }\end{array}$ & 2017 \\
\hline A10 & $\begin{array}{l}\text { Training Transdisciplinary } \\
\text { Educators: Intercultural } \\
\text { Learning and Regenerative } \\
\text { Practices in Ecuador }\end{array}$ & $\begin{array}{l}\text { Javier Collado-Ruano } \\
\text { Mario Madroñero-Morillo } \\
\text { Freddy Álvarez-González } \\
\text { National University } \\
\text { of Education (UNAE) } \\
\text { - Equador }\end{array}$ & $\begin{array}{l}\text { Studies in } \\
\text { Philosophy and } \\
\text { Education }\end{array}$ & 2019 \\
\hline A11 & $\begin{array}{l}\text { Lugares de Resistência na } \\
\text { Formação Inicial de } \\
\text { Professores: Por } \\
\text { Matemática(s) Decoloniais }\end{array}$ & $\begin{array}{l}\text { Diego Matos } \\
\text { Universidade Federal do } \\
\text { Estado do Rio de Janeiro } \\
\text { (UNIRIO) - Brasil } \\
\text { Wellerson Quintaneiro } \\
\text { Centro Federal de Educação } \\
\text { Tecnológica do Rio de } \\
\text { Janeiro (CEFET-RJ) - Brasil }\end{array}$ & $\begin{array}{l}\text { Perspectivas da } \\
\text { Educação } \\
\text { Matemática - } \\
\text { INMA/UFMS }\end{array}$ & 2019 \\
\hline A12 & $\begin{array}{l}\text { Preparing Teachers as } \\
\text { Democratic Professionals }\end{array}$ & $\begin{array}{l}\text { Ken Zeichner } \\
\text { University of Washington - } \\
\text { EUA }\end{array}$ & $\begin{array}{l}\text { Action In Teacher } \\
\text { Education }\end{array}$ & 2019 \\
\hline A13 & $\begin{array}{l}\text { Going to school for the first } \\
\text { time: inclusion committee } \\
\text { members increasing the } \\
\text { number of students with } \\
\text { disabilities in primary } \\
\text { schools in Kenya }\end{array}$ & $\begin{array}{l}\text { Brent C. Elder } \\
\text { Rowan University, } \\
\text { Glassboro, NJ - EUA } \\
\text { Bernard Kuja } \\
\text { Great Lakes University of } \\
\text { Kisumu, Kisumu - Quênia }\end{array}$ & $\begin{array}{l}\text { International } \\
\text { Journal of Inclusive } \\
\text { Education }\end{array}$ & 2019 \\
\hline A14 & $\begin{array}{l}\text { Por uma poética decolonial } \\
\text { no ensino superior: } \\
\text { contribuições da didática na } \\
\text { formação de } \\
\text { professores(as). }\end{array}$ & $\begin{array}{l}\text { Jilvania Lima Dos Santos } \\
\text { Bazzo; Universidade Federal } \\
\text { de Santa Catarina, Brasil }\end{array}$ & $\begin{array}{l}\text { Revista Pedagógica: } \\
\text { Revista do } \\
\text { programa de Pós- } \\
\text { graduação da } \\
\text { Unochapecó }\end{array}$ & 2019 \\
\hline
\end{tabular}


Em A5 foi discutida a articulação entre a prática docente e as coordenadas teóricas em um processo de transformação e recriação de um currículo contra hegemônico de formação de professores na Argentina, numa proposta decolonial. A pesquisa foi realizada com 250 formadores de professores. Alguns professores demonstraram incerteza, mas outros esperança em melhorias para o cenário da educação. A estratégia inicial teve objetivo de repensar a prática pedagógica para levar os docentes a um novo posicionamento sobres a estruturas hegemônicas da educação. Um dos eixos centrais do processo foi promover as trocas de experiências entre os professores, o que contribuiu para identificar a colonialidade e avançar para sua desestruturação (HUERGO; MORAWICKI, 2010). Os autores finalizam afirmando que desafiar a transformação curricular da formação docente nessa perspectiva não constituiu em substituir as vozes ou teorias por novas vozes e/ou teorias nem mudar as a forma como é vista a educação e o ensino, mas reconhecer os sujeitos, suas práticas e transformar as subjetividades que veem.

O artigo A6 teve como objetivo mostrar o processo de mudanças na formação de professores proposto na Bolívia, em 2006, uma reforma educacional descolonizante. A nova reforma visou a desconstruir processos históricos de negação e exclusão indígena na educação e promover uma reestruturação da sociedade boliviana e reaver o patrimônio epistemológico, cultural e linguístico indígena boliviano por meio da educação. Assim, ficou estabelecido, em lei, que a formação de professores deveria: formar profissionais críticos, reflexivos, autocríticos, inovadores e orientados para a pesquisa, comprometidos com a democracia, com as transformações sociais e a inclusão plena de todos os bolivianos na sociedade (LOPES CARDOZO, 2012). A nova reforma educacional foi contestada à medida em que diferentes estratégias foram desenvolvidas, por vários atores e em diferentes escalas, para fazer cumprir ou resistir ao novo discurso e às iniciativas políticas relacionadas à reforma (LOPES CARDOZO, 2012). A pesquisa mostrou um aumento de tensões entre 
cidadãos indígenas e não-indígenas em diferentes regiões do país, visto que as identidades indígenas têm sido adotadas pelos recém professores, resgatando a herança cultural e linguística, sobrenomes e vestimenta em ambientes formais, o que não foi unanimidade entre os cidadãos bolivianos (LOPES CARDOZO, 2012).

No Artigo A7, a autora discute sobre práticas pedagógicas com licenciandos em Letras - Português a fim de propor possibilidades para uma educação decolonial. A autora referencia-se em Paulo Freire e Boaventura de Souza Santos para reflexão e proposição de práticas pedagógicas que se contrapõem à educação bancária, na busca de uma educação transformadora, dessa forma, transformar a sala de aula em um espaço de resistência aos modelos impostos padronizadores do ensino (ROCHA, 2017). A autora afirma que os futuros professores precisam dessas experiências pois permitirão "outras possibilidades para uma prática docente mais significativa no sentido de formar cidadãos críticos e lúcidos" (ROCHA, 2017, p. 6).

No artigo A8 a autora discutiu a situação vulnerável dos refugiados que enfrentam dificuldades para manter o direito à educação. A autora questiona se não deveria ser uma política global e expõe questões de conflito sobre a educação de refugiados, os quais devem ser educados e aculturados para retornar ao seu país de origem, para a integração em seu país anfitrião, ou em preparação para ir para uma nação desenvolvida? Os alunos devem ser ensinados nos campos de refugiados ou nas escolas locais? Devem ser priorizados programas que para superar traumas e adquirir habilidades de vida ou regular disciplinas escolares como matemática e ciências? (FICARRA, 2017). A autora constata na literatura que a educação em campos de refugiados tem acesso desigual quanto a gênero e idade. A maioria dos refugiados do mundo vivem no Sul Global e outros, eventualmente, são reassentados no Norte Global, como Estados Unidos e Canadá. Segundo a autora, pesquisadores canadenses, estadunidenses e australianos obtiveram resultados em pesquisas que explicitam o preconceito e a discriminação enfrentados por estes estudantes que foram 
racializados e homogeneizados por professores limitando sua motivação educacional, desempenho e oportunidades. Dessa forma, Ficarra (2017) defende que os gestores educacionais possuem papel importante para a formulação e a implementação de políticas nas escolas e de requerer uma formação de professores mais efetiva nas questões multiculturais. Recomenda que professores em formação e em serviço estudem sobre autores e grupos refugiados para que não fortaleçam estereótipos sobre os estudantes (FICARRA, 2017).

Em A9, Sprecher (2017) discute a necessidade de preparar professores para atuar em salas de aula globalizadas no contexto estadunidense. As imigrações têm trazido pessoas de todo o mundo para as comunidades americanas e, dessa forma, "as salas de aula dos EUA são ambientes locais-globais, em que crianças de diversas origens étnicas, socioculturais, nacionais e linguísticas interagem diariamente" (SPRECHER, 2017, p. 27, tradução nossa). Os estudantes trazem consigo múltiplas epistemologias, expectativas, experiências e essas demandas diversificadas precisam ser atendidas no âmbito pedagógico. A autora considera haver uma desconexão entre as posições dos estudantes e da maioria dos professores que são compostos em geral por brancos e de classe média. Segundo Sprecher (2017), um multiculturalismo póscrítico local-global incorpora pedagogias e pluralismo relevantes nos currículos e ambiente escolar possibilitando oportunidades educacionais que evitem a marginalização eurocêntrica de grupos não dominantes. Sprecher (2017) destaca que as propostas de formação de professores pesquisadores só serão viáveis com uma mudança no papel profissional do professor, uma mudança nas estruturas de ensino, para fornecer aos professores tempo e recursos para realizar e compartilhar suas pesquisas, desenvolver capacidades de tomada de decisão e autonomia para implementar praticas pedagógicas (SPRECHER, 2017).

No artigo A10 os autores apresentam o modelo de formação transdisciplinar desenvolvido na Universidade Nacional de Educação (UNAE) do Equador baseado nas 
cosmovisões ancestrais de Bem Viver, que, a partir da leitura do mundo, incorpora a visão de mundo andina e amazônica como eixo da enunciação epistemológica, política e educacional. Dessa forma o Bem Viver emerge como uma possibilidade de construir outros mundos possíveis e como uma alternativa ao 'desenvolvimento' ocidental. As Ciências da Educação para o Bem Viver apresentam uma proposta decolonial a partir da qual o ser humano modifica suas relações com a natureza. Esta pedagogia de bioalfabetismo derivada do Bem Viver cria um diálogo interepistemológico com o saber científico e une a ciência com espiritualidade (COLLADO-RUANO et al., 2019). Dessa forma, o Bem Viver deve permear a formação, a pesquisa, a formação continuada e os vínculos comunitários para criar uma relação harmoniosa entre os humanos e a Pachamama - nossa Mãe Terra. Portanto, a promoção do Bem Viver nas instituições educacionais é um elemento essencial no desenvolvimento profissional dos futuros professores da região andina.

Em A11 os autores discutem a formação de professores que ensinam matemática e os saberes docentes necessários a partir das proposições de diversos autores sobre as abordagens teóricas para fortalecer os saberes desses profissionais. A partir da lente decolonial, propõem deslocar as discussões para o campo político e buscar, a partir de brechas e fissuras, analisar que discursos são omitidos sobre os saberes matemáticos para o ensino e prática docente e sobre a profissionalização (MATOS; QUINTANEIRO, 2019). A pesquisa foi realizada com 35 estudantes do curso de licenciatura em matemática. Os resultados indicaram, a partir dos discursos, dimensões de colonialidade na formação de professores que emergiram na análise em três eixos: "a valorização social do conhecimento matemático, a desvalorização social da profissão docente e o silenciamento do conhecimento matemático para o ensino na formação de professores"; relacionados à colonialidade do saber, de forma entrelaçada (MATOS; QUINTANEIRO, 2019, p. 573). O trabalho traz contribuições 
teóricas sobre a formação de professores que ensinam matemática e a reconstrói numa perspectiva decolonial.

No artigo A12, Zeichner (2019) aborda conceitos sobre o profissionalismo no ensino no âmbito estadunidense e discute o profissionalismo democrático como uma alternativa para a formação de professores, que possa diminuir as tensões entre a escola pública, as comunidades e os programas de formação de professores. Nesse sentido, defende uma formação decolonial que envolva as comunidades e os programas de base comunitária, trazendo os saberes locais para o ambiente de formação de professores, cujo foco deve ser a equidade e a justiça social para subverter a lógica hierárquica de poder, criando base para novas alianças entre professores e movimentos sociais comunitários em comunidades marginalizadas que buscam um papel ativo na transformação de suas próprias comunidades (ZEICHNER, 2019). Os professores precisam compreender a importância de desenvolver relações de respeito mútuo com parceiros comunitários e incluí-los em todas as fases de melhoria contínua do programa de formação, incluindo a conceituação e desenvolvimento de práticas e estruturas (ZEICHNER, 2019).

O artigo, A13 teve como objetivo mostrar como a formação de comitês de inclusão e a formação de professores para a educação inclusiva possibilitou que pessoas com deficiência acessassem a escola pela primeira vez no Quênia. A metodologia utilizada na pesquisa foi a abordagem de pesquisa participativa de base comunitária (CBPR) para a formação e a manutenção dos comitês de inclusão, a partir do qual foi desenvolvido o treinamento de professores. Segundo dados do Ministério da Educação do Quênia (em 2008), mais de um milhão de estudantes com deficiências são excluídos de oportunidades educacionais equitativas (ELDER \& KUJA, 2018). A implementação das estratégias da pesquisa foi alinhada com os objetivos do comitê de inclusão e desenvolvidas em conjunto com base na justiça social e com abordagens ativistas para descolonizar. Os autores destacam que os pesquisadores decoloniais têm 
um papel importante na realização de atos que se concentram na justiça social. 0 estudo foi orientado também pelo trabalho de Paulo Freire com a Pedagogia do oprimido, por meio dos círculos de cultura e a pesquisa de base comunitária participativa. O projeto possibilitou a pensar e questionar os fatores complexos de segregação existentes no sistema de ensino queniano e, partir disso, foi possível ter uma compreensão melhor de como criar salas de aula primárias mais inclusivas no país (ELDER \& KUJA, 2018). A partir dessas abordagens para o desenvolvimento e a expansão de um sistema educacional sustentável e inclusivo, o governo queniano passou a considerar a replicação dessa prática em escala nacional. Como resultado deste trabalho conjunto está em curso uma revisão nacional sobre a política de educação especial de inclusão no país.

No artigo A14, a autora discute sobre as contribuições da Didática para a formação de professores para pensar em torno do contraponto entre a didática 'instrumental' e a didática 'fundamental', proposta por Vera Candau, que compreende as dimensões técnica, humana e política da educação como indissociáveis da prática pedagógica. A autora considera que na formação de professores, a Didática contribui para que cada um seja capaz de aprender com o outro a escutar, a desenvolver uma fala acolhedora, amorosa, um pensar e um agir ético. A autora afirma que a Didática desempenha um papel importante na formação de professores e pensar sob a ótica de uma poética decolonial contribui para que ela cumpra o seu papel social de formar professores críticos, que concebam o ensino como um ato de decisão, conhecimento e criação (BAZZO, 2019).

\subsection{ReLAÇões ÉtNICO RACIAIS NA FoRMAÇÃo de PROFESSORES}

Nas discussões dos artigos, as questões relacionadas a africanidades na formação de professores possuem um papel importante para construir uma escola antirracista. Os artigos apresentam discussões sobre a formação do professor, os 
conflitos, os desafios e a importância de tratar questões, como racismo, práticas colonizadoras e outras questões relacionadas (Quadro 4).

Quadro 4: Dados dos artigos agrupados em 'Relações étnico raciais na formação de professores'. Fonte: Os autores.

\begin{tabular}{|c|c|c|c|c|}
\hline \multicolumn{5}{|c|}{ Relações étnico raciais na formação de professores - Afrodescendência } \\
\hline Cód. & Título & Autores(as) & Periódico & Ano \\
\hline A15 & $\begin{array}{l}\text { Afro-Brazilian Ancestrality: } \\
\text { critical perspectives on } \\
\text { knowledge and development. }\end{array}$ & $\begin{array}{l}\text { Alexandre Emboaba Da Costa } \\
\text { Queen's University, Kingston, } \\
\text { Ontario, Canadá }\end{array}$ & $\begin{array}{l}\text { Third World } \\
\text { Quarterly. }\end{array}$ & 2010 \\
\hline A16 & $\begin{array}{l}\text { Representaciones sociales sobre } \\
\text { afrodescendencia: currículum, } \\
\text { práctica y discurso pedagógico } \\
\text { del professorado }\end{array}$ & $\begin{array}{l}\text { Yeison Arcadio Meneses - } \\
\text { Copete } \\
\text { Facultad de Educación de la } \\
\text { Universidad de Antioquia - } \\
\text { Colômbia }\end{array}$ & Entramado & 2014 \\
\hline A17 & $\begin{array}{l}\text { A implementação da lei no } \\
\text { 10.639/2003 no estado de Mato } \\
\text { Grosso do Sul e a formação } \\
\text { continuada de professores: uma } \\
\text { perspectiva emancipatória e } \\
\text { decolonial }\end{array}$ & $\begin{array}{l}\text { Eugenia Portela de Siqueira } \\
\text { Marques } \\
\text { Universidade Federal da } \\
\text { Grande Dourados (UFGD) }\end{array}$ & $\begin{array}{l}\text { Revista } \\
\text { Contemporâne } \\
\text { a de Educação }\end{array}$ & 2017 \\
\hline A18 & $\begin{array}{l}\text { Professora, mulher negra e a lei } \\
\text { da diversidade }\end{array}$ & $\begin{array}{l}\text { Lori Hack de Jesus } \\
\text { Universidade do Estado de } \\
\text { Mato Grosso - Brasil }\end{array}$ & $\begin{array}{l}\text { Periferia: } \\
\text { educação, } \\
\text { cultura e } \\
\text { comunicação }\end{array}$ & 2018 \\
\hline A19 & $\begin{array}{l}\text { Educação, relações } \\
\text { etnicorraciais e } \\
\text { decolonização na práxis de } \\
\text { professores/as. }\end{array}$ & $\begin{array}{l}\text { Elison Antonio Paim } \\
\text { Patrícia Magalhães Pinheiro; } \\
\text { Josiane Beloni de Paula } \\
\text { Universidade Federal de } \\
\text { Santa Catarina - Brasil }\end{array}$ & $\begin{array}{l}\text { PERSPECTIVA: } \\
\text { Revista do } \\
\text { Centro de } \\
\text { Ciências da } \\
\text { Educação }\end{array}$ & 2019 \\
\hline
\end{tabular}

No artigo A15, o autor discutiu a ancestralidade afro-brasileira e considerou unir os culturalismos da ideologia nacional ao das políticas de desenvolvimento multicultural com ancestralidade. Delineou uma perspectiva crítica sobre raça, cultura e desenvolvimento, indicando o 'pensar com' em vez de 'pensar', as lutas afrodescendentes no contexto brasileiro. 'Pensar com' possibilita conhecimento crítico sobre o desenvolvimento que nasce das lutas afro-brasileiras para considerar como 
esse conhecimento é mobilizado para a transformação da política, das instituições e das práticas sociais (DA COSTA, 2010). No que se refere à ancestralidade, à educação e à formação de professores, o autor relatou sobre a implementação e alguns resultados de um projeto educacional para implementar a Lei 10639/2003 em escolas municipais de Ribeirão Preto -SP, o Projeto Baobá - Educando para a Igualdade ÉtnicoRacial. O projeto teve a ancestralidade, como filosofia, formando professores e gestores. A implementação do projeto evidenciou as dificuldades sobre a abordagem do tema refletindo a ideia cultural sobre a desigualdade racial. O projeto foi realizado em parceria com Centro Cultural Orunmilà, que resiste enfatizando sua autonomia organizacional, fiscal e política. O projeto foi importante, pois no currículo escolar e na sala de aula, os negros, quando aparecem, refletem a subalternização. Além disso, professores, administradores e gestores não recebem formação sobre 'raça', desigualdade racial ou a experiência histórica específica dos afro-brasileiros, em nível superior (DA COSTA, 2010). Para o autor, o silêncio curricular sobre 'raça' e afrobrasileiros é institucionalizado na sociedade e no discurso da formação universitária. Assim, foi realizado um curso para formação de professores e gestores sobre a temática étnico-racial (Da Costa, 2010). O autor observou mudanças da postura dos professores após a formação, visto que nem todos acreditavam na necessidade dessa discussão. A análise de entrevistas com professores cursistas indicou que os professores e alunos mudaram a perspectiva sobre a África, a história e a cultura afrobrasileiras, bem como as contribuições do povo negro para a construção do país.

O artigo A16 teve como foco investigar os discursos e práticas pedagógicas de professores universitários e professores em formação, com relação ao currículo e se aprofundar no universo complexo da reprodução de relações, práticas, discursos, imaginários e representações sociais nos contextos escolares e acadêmicos (estudantes e docentes) e dos conteúdos. Analisou as representações sociais sobre afrodescendência nos processos de formação de professores da Faculdade de 
Educação da Universidade de Antióquia na Colômbia (MENESES-COPETE, 2014). O autor buscou desvelar linguagens, relações e práticas sociais possibilitadas pelo currículo explícito e/ou oculto. Essas representações sociais reproduzidas nos processos de formação de professores podem refletir na sala de aula e no desempenho do futuro professor. Percebeu-se que tanto os professores em atividade, quanto dos professores em formação apresentam as mesmas representações sociais, da diversidade étnico cultural, em particular da afrodescendência no currículo e nas práticas pedagógicas. Assim, os discursos e práticas identiárias dos professores são evidenciados a partir da pedagogia popular, pedagogias críticas, discursos descolonias, pedagogias sociais e estudos interculturais, que confrontam o caminho da igualdade na educação e na escola, particularmente na formação de professores (MENESESCOPETE, 2014).

No artigo A17, a autora faz um estudo sobre as mudanças trazidas pela lei 10639/2003, para o currículo escolar, discute os desafios dessas mudanças para a formação docente e apresenta um estudo realizado em escolas públicas do Mato Grosso do Sul, a partir de um questionário semiestruturado que foi respondido por 572 (quinhentos e setenta e dois) profissionais (professores, gestores escolares, coordenadores pedagógicos, bibliotecários e assistentes de bibliotecas) conforme indicado por Marques (2017). A pesquisa foi fundamentada nos estudos pós-coloniais. No estudo com os profissionais da educação, a autora observou que: a lei promoveu reflexões antes ausentes no currículo escolar; ainda há desconhecimento por parte de profissionais sobre a lei e muitos consideram não ser necessário essas discussões, reproduzindo o discurso da falsa democracia racial. Os depoimentos apontam a falta de formação continuada e a recusa de professores em abordar o tema em sala, por não 'saber fazer' ou por não 'querer fazer' (MARQUES, 2017). Assim, ela sugere a formação continuada como uma forma de assumir compromisso e responsabilidade com a educação antirracista e intercultural. Sobre o racismo no ambiente escolar, os 
resultados mostraram que os profissionais ignoram ou silenciam sobre o tema, mesmo sabendo que acontece (MARQUES, 2017).

No artigo A18, a autora relata, a vivência de uma professora negra que desenvolveu um trabalho importante para a discussão das questões étnico raciais na escola. Partindo da premissa de que ainda há um longo caminho para que as escolas de educação básica atendam às Leis 10.639/03 e 11.645/08, a autora observa que essa atividade ainda fica caracterizada na escola como uma atribuição dos professores negros ou indígenas (JESUS, 2018). A autora afirma que esse fato foi percebido pelos diversos programas como PIBID, projetos de pesquisa e de extensão desenvolvidos pelas universidades dentro da escola. Considera ainda que professores negros e indígenas assumem essa função por ser delegada pelos colegas, por serem mais sensíveis e compreenderem melhor as questões raciais, a necessidade e a importância da implementação da lei e de políticas de valorização dos povos negros e indígenas no âmbito escolar. Por outro lado, professores brancos por vezes alegam não possuir preparo para abordar essas questões em sala de aula e não estarem aptos a lidar com questões de racismo na escola, o que demonstra uma necessidade de se investir na formação de todos os professores (JESUS, 2018). A autora destaca que a professora e a maior parte dos docentes demonstram compreender que o racismo está presente na sociedade e que essas ações são necessárias. A autora considera que o trabalho de professores negros e indígenas "a partir dos seus pontos de vista, dos seus sentimentos e suas vivências são vozes que ecoam, que denunciam e anunciam uma outra forma de ver o mundo em que vivemos" (JESUS, 2018, p. 77).

No artigo A19, os autores(as) discutem aspectos teóricos da colonialidade do poder, do ser e do saber por considerar que essa discussão possibilita uma nova epistemologia que rompe com as visões dualistas e antagônicas apresentadas por Anibal Quijano, Catherine Walsh, Nelson Maldonado-Torres (colonizador/colonizado, branco/negro, homem/mulher, opressor/oprimido; norte/sul, etc) e compreende as 
intersecções entre as identidades sociais (PAIM et al., 2019). O trabalho com enfoque nas questões etnicoraciais na formação de professores foi desenvolvido a partir da investigação sobre a implantação da lei 11645/2008 na práxis de professores, a partir de entrevistas, narrativas e compartilhamento de experiências, no evento "Encontro sobre o Poder Escolar". Os autores(as) analisaram as memórias, experiências e práticas dos professores(as) que desenvolveram atividades focadas nas questões de resistências e na valorização de negros e indígenas na sociedade brasileira, trazendo uma perspectiva decolonial e antirracista com a interface dos autores apresentados. Os autores destacam a importância das práticas emancipatórias e de resistência dos professores para transformar a realidade social.

\subsection{Decolonialidade EpISTÊmica e Questões de GÊNero na Formação de Professor}

As questões de gênero, Teoria Queer e mudança nas práticas pedagógicas são outros temas abordados por trabalhos no âmbito da decolonialidade promovendo resistência e desobediência epistêmica. Na formação de professores, esses temas são importantes por promover decolonialidade epistemológicas, respeito às diferenças e possibilitar a abordagem de questões diversas e minimizar a repetição de comportamentos coloniais (Quadro 5).

Quadro 5: Dados dos artigos agrupados em Questões de gênero e sexualidade na formação de professores. Fonte: Os autores.

\begin{tabular}{|c|c|c|c|c|}
\hline \multicolumn{5}{|c|}{ Decolonialidade e questões de gênero e sexualidade } \\
\hline Cód & Título & Autores (as) & Periódico & Ano \\
\hline A20 & $\begin{array}{l}\text { Perspectiva de género en las } \\
\text { carreras de Licenciatura en } \\
\text { Ciencias Sociales y Geografía } \\
\text { en cuatro universidades } \\
\text { públicas de Colombia }\end{array}$ & $\begin{array}{l}\text { ZAIDA LIZ Patiño } \\
\text { Gómez; LAURA } \\
\text { NARANJO Villa; } \\
\text { MARGGIE SERNA } \\
\text { Felipe } \\
\text { Universidad del Valle - } \\
\text { Colômbia }\end{array}$ & $\begin{array}{l}\text { Revista Perspectiva } \\
\text { Geográfica }\end{array}$ & 2018 \\
\hline A21 & $\begin{array}{l}\text { Pedagogías queer y polifonías } \\
\text { del sur: transgresiones y } \\
\text { afecciones em la educación en } \\
\text { el profesorado }\end{array}$ & $\begin{array}{l}\text { Francisco Ramallo; } \\
\text { Juan Ariel Gómez; } \\
\text { Luis Porta }\end{array}$ & $\begin{array}{l}\text { Revista de Ciências } \\
\text { Humanas }\end{array}$ & 2018 \\
\hline & & & & \\
\hline
\end{tabular}




\begin{tabular}{|l|l|l|l|}
\hline \hline & $\begin{array}{l}\text { Facultad de } \\
\text { Humanidades } \\
\text { (UNMdP) - Argentina }\end{array}$ & & \\
\hline
\end{tabular}

No artigo A20, Patiño Gómez et. al (2018) avaliam o enfoque de gênero nos programas de graduação em licenciaturas em Ciências Sociais e em Geografia de quatro universidades públicas da Colômbia que formam os novos professores da área. As autoras discutem o Gênero como uma manifestação do pensamento decolonial em três categorias de análise: gênero, etnia (indígena e afrodescendente) e identidade. Os resultados indicam que há pouco enfoque de gênero no ensino de geografia nos cursos de licenciatura, tanto com relação ao conteúdo, à literatura e reflexões, quanto na pesquisa. As autoras destacam que o pouco enfoque na questão de gênero nos trabalhos de estudantes, em termos de conteúdo, referências de autoras e outros, faz parte de um processo sistemático de uma sociedade que torna invisível e favorece as desigualdades, a discriminação e a subordinação das mulheres numa sociedade masculina (PATIÑO GÓMEZ et al., 2018). Para as autoras, um desafio é que o país e a América Latina sejam capazes de construir um caminho teórico que possibilite a discussão crítica e entrelace as discussões de gênero e a geografia fazendo uso de teorias feministas em suas análises, não separando o gênero da geografia.

No artigo A21, os autores discutem a construção da pedagogia Queer a partir de sentidos imediatos e polifônicos, a fim de evidenciar sua importância para a educação e para a formação docente. Para isso, dialoga com o projeto político do Sul e as perspectivas decoloniais de educação. Intenciona transgredir as experiências de investigação, práticas docentes e ativismos no contexto da formação de professores. A escrita parte dos movimentos produtivos que as pedagogias Queer - ou seja, aquelas que pensam na intersecção entre subjetividade, sexualidade (dissidente) e educação provocam na leitura diária, na educação em geral e na formação de professores em particular. Entre repetições e diferenças nesse âmbito, as pedagogias Queer possuem 
intersecções e convergências com as perspectivas decoloniais que propõem transgredir e intervir contra a normatividade e essencialismos nas teorias e práticas educacionais. Uma pedagogia Queer no contexto institucional e normalizador da formação de professores propõe construir genealogias outras que emergem de fora dos centros de produção de conhecimento, busca estratégias de insurgência e resistência, a partir de conhecimentos periféricos subalternizados, que contrapõe à pedagogia padronizada (RAMALLO et al., 2018). Dessa forma, propõe uma decolonialidade da formação de professores a partir da discussão de pedagogias outras.

Ao passar por todos esses trabalhos, retomamos as questões que nos orientaram nesse caminho: Como a formação de professores tem sido discutida no âmbito de artigos que têm a decolonialidade como enfoque? Como o tema da (de)colonialidade é discutido e/ou abordado no âmbito dessas formações?

Foi possível perceber que os trabalhos em torno da formação de professores na perspectiva decolonial possuem um amplo espectro de discussões, na busca por uma educação transformadora. As pesquisas foram realizadas em diversos contextos e realidades, num movimento de resistência e reexistência para a superação da visão unidimensional de um mundo diverso e plural e romper estruturas que mantêm as relações de poder na sociedade.

Os trabalhos no campo da educação indígena demonstram que é possível trazer para a formação de professores (indígenas e não indígenas) discussões que promovam a reflexão sobre a práxis e deslocamentos epistemológicos que possibilitam o respeito às diferenças, o reconhecimento da importância de saberes outros e do papel político pedagógico da docência. Essas ações rompem com a hierarquização de saberes ocidentais e impactam a prática docente fazendo da escola um espaço de resistência, 
assim como o é a escola indígena e seus professores, como visto em como em Barbosa (2018).

Os trabalhos de resistência, política e justiça social nos fazem refletir sobre a responsabilidade e amplitude do papel do professor para contextos em realidades diversas, mas que se entrelaçam, visto que as lacunas sobre a formação persistem comuns.

Um ponto comum nas pesquisas é o fato de que, em geral, os professores indicam que não se sentem preparados para ensinar para a diversidade, apontando anseio por uma formação nesse sentido. Demonstram reconhecer apenas os conhecimentos hegemônicos e nem sempre possuem a consciência de que essa percepção eurocentrada é consequência de uma formação que mantém sistemas de desigualdade. Os artigos destacam a universidade como reprodutora do conhecimento hegemônico como em Da Costa (2010), Zeicnher (2019) e a escola como uma instituição que a mantém.

Os trabalhos que propõem desobediência epistêmica, resistências políticas e de justiça social entram em diversos contextos desde conflitos por uma educação decolonial na Bolívia, como Cardozo(2012) a discussões sobre as condições educacionais em campos de refugiados pelo mundo como em Ficarra (2017) o que demonstra que as lutas em prol de justiça social ultrapassam fronteiras e o professor pode atuar como aliado para transformação desses contextos. O trabalho de Huergo e Morawicki (2010) busca mobilizar professores argentinos para um outro olhar sobre a escola, o currículo e a educação.

A pesquisa de Elder \& Kuja (2018), focou na prática e no 'novo olhar' dos professores e a comunidade para os estudantes com deficiência, fortalecendo a discussão sobre a importância da formação dos professores, tanto inicial quanto continuada, numa perspectiva decolonial. 
Nos trabalhos que tratam das sobre relações étnico-raciais, constatamos discussões relacionadas à Lei 10639/2003 e à Lei 11645/2008. Em geral, os docentes pesquisados apontam que há desconhecimento sobre o tema e/ou falta de preparo para inserir os conteúdos em sala de aula. Em alguns casos, afirmam que não percebiam a importância de discutir racismo na escola, consequência da noção equivocada de 'democracia racial' e de ausência dessa discussão no âmbito de formação. Fica evidente a urgência em discutir com professores a atuação em sala de aula numa perspectiva decolonial, sensibilizando-os para as questões étnico-raciais em defesa de uma educação antirracista.

Os trabalhos de Barbosa (2018) e Matos (2019) ocorreram no âmbito da formação de professores de matemática. Ambos trouxeram indicativos importantes: por um lado, em Barbosa (2018), os licenciandos que atuaram com professores indígenas puderam confrontar de forma crítica os saberes obtidos na formação e os conteúdos do currículo universitário; por outro lado em Matos e Quintaneiro (2019), houve um silêncio nas discussões sobre os conhecimentos da matemática escolar para a sala de aula, na formação universitária. Essas percepções se entrelaçam e indicam que ainda há um caminho a percorrer no sentido de trazer para a formação a amplitude do contexto social e cultural em que a escola está inserida. Essa é uma discussão necessária no âmbito da formação de professores de ciências e matemática que pode trazer um outro olhar para os saberes construídos em lugares outros e desconstruir a ideia de uma ciência fixa e imutável, mas que se constrói e se reconstrói na práxis. Apenas dois trabalhos discutiram questões de gênero e sexualidade e apontam para uma decolonialidade epistemológica a partir de outros olhares, como a da pedagogia Queer, que propõe insurgir contra normatividades das teorias e práticas educacionais, que mantêm as relações hierarquizadas entre sujeitos. 


\section{CONCLUSÕES}

Várias alternativas são discutidas para que se gere mudanças na sociedade por meio da educação, no que tange à formação de professores e à proposta decolonial. Sugerem-se mudanças nas políticas educacionais, mudanças curriculares para a incorporação de conteúdos que atendam a diversidade e à pluralidade dos sujeitos na sociedade, o profissionalismo democrático incorporando os saberes locais para o ambiente de formação, entre outras possibilidades.

Nesse contexto geral, ainda há a necessidade de ampliarmos essas as discussões com professores, para oferecer uma formação para além do conhecimento específico, discutindo problemas sociais e políticos, numa perspectiva decolonial de insurgência e resistência que se contraponha às hegemonias dominantes. Nos diversos contextos, os autores consideram que as ações durante a formação inicial e/ou continuada vão interferir na ação, nas construções e na prática docente do professor e/ou futuro professor. Contudo, faz se necessário estar atento também ao papel profissional de professores que precisam de recursos, tempo de planejamento, valorização profissional e condições favoráveis de trabalho para investir na sua formação.

\section{AGRADECIMENTOS}

O presente trabalho foi realizado com apoio parcial da Coordenação de Aperfeiçoamento de Pessoal de Nível Superior - Brasil (CAPES) - Código de Financiamento 001.

Agradecemos ao Instituto Federal do Espírito Santo (Ifes) e à Universidade Federal do Rio de Janeiro (UFRJ) pela oportunidade de pesquisar, aprender, reaprender numa construção permanente de busca pelo conhecimento científico, tecnológico, social e educacional. 


\section{REFERÊNCIAS}

BALLESTRIN, L. América Latina e o giro decolonial. Revista Brasileira de Ciência Política, n. 11 , p. 89-117, p. 89-117, ago. 2013. https://doi.org/10.1590/S010333522013000200004

BARBOSA, G. dos S. Extensão universitária: Contribuições de professores guarani para a formação inicial de professores de matemática. Revista Espaço Pedagógico, Passo Fundo, v. 25, n. 3, p. 777-800, set./dez. 2018.

BAZZO, J. L. DOS S. Por uma poética decolonial no ensino superior: contribuições da didática na formação de professores(as). Pedagógica: Revista do programa de Pósgraduaçao em Educaçao - PPGE, v. 21, n. 1, p. 115-130, 2019.

CASTRO, D. J. F. DE A.; MONTEIRO, B. A. P. A (re)existência de mulheres na forma de saberes ancestrais: repensando outras relações entre ciência, ambiente e educação no contexto pandêmico. Revista Sergipana de Educação Ambiental, v. 7, n. Especial, p. 116, 29 out. 2020.

COLLADO-RUANO, J.; MADROÑERO-MORILLO, M.; ÁLVAREZ-GONZÁLEZ, F. Training Transdisciplinary Educators: Intercultural Learning and Regenerative Practices in Ecuador. Studies in Philosophy and Education, v. 38, n. 2, p. 177-194, mar. 2019.

DA COSTA, A. E. Afro-Brazilian Ancestralidade: critical perspectives on knowledge and development. Third World Quarterly: Relocating Culture in Development and Development in Culture, v. 31, n. 4, p. 655-674, 1 jun. 2010.

DUTRA, D. S.A.; CASTRO, D. J. F. A.; MONTEIRO, B.A.P. Educação em ciências e decolonialidade: em busca de caminhos outros. In: MONTEIRO, B. A. P.; DUTRA, D. S. A. ; CASSIANI, S. ; SANCHEZ, C. ; OLIVEIRA, R. D. V. L.. (Org.). Decolonialidades na Educação em Ciências (Coleção culturas, direitos humanos e diversidades na educação em ciências). 1ed. São Paulo: Livraria da Física, 2019, v. 1, p. 1-17

ELDER, B. C.; KUJA, B. Going to school for the first time: inclusion committee members increasing the number of students with disabilities in primary schools in Kenya. International Journal of Inclusive Education, v. 23, n. 3, p. 261-279, 30 jan. 2018.

FICARRA, J. Comparative International Approaches to Better Understanding and Supporting Refugee Learners. Issues in Teacher Education, v. 26, n. 1, p. 12, 2017.

FREIRE, Paulo. Pedagogia do oprimido. 18/46. ed. Rio de Janeiro: Editora Paz e Terra, 1988/2005.

FREIRE, Paulo. Pedagogia da autonomia: saberes necessários à prática educativa. São Paulo. Paz e Terra. 1996. 
HUERGO, J.; MORAWICKI, K. Una reescritura contrahegemónica de la formación de docentes. Nomadas (Colombia), $\mathrm{n}$. 33, 2010. http://search.proquest.com/docview/2046662090/?pq-origsite=primo JESUS, L. H. DE. Professora, mulher negra e a lei da diversidade. Periferia, v. 10, n. 2, p. 67-79, 10 jul. 2018.

LOPES CARDOZO, M. T. A. Transforming pre-service teacher education in Bolivia: from indigenous denial to decolonisation? Compare: A Journal of Comparative and International Education, v. 42, n. 5, p. 751-772, set. 2012. Disponível em: https://doi.org/10.1080/03057925.2012.696040.

MARQUES, E. P. DE S. A implementação da lei 10.639/2003 no estado de Mato Grosso do Sul e a formação continuada de professores: uma perspectiva emancipatória e decolonial. Revista Contemporânea de Educação, v. 12, n. 23, p. 51-68, 2017.

MATOS, Diego. QUINTANEIRO, Wellerson. Lugares de Resistência na Formação Inicial de Professores: Por Matemática(s) Decoloniais. Revista do Programa de PósGraduação em Educação Matemática da Universidade Federal de Mato Grosso Do Sul (UFMS). Campo Grande, v. 12, n. 30, p. 559-582, 2019

MENESES-COPETE, Y. A. Representaciones sociales sobre afrodescendencia: currículum, práctica y discurso pedagógico del profesorado. ENTRAMADO, v. 10, n. 2, p. 250-271, 2014.

MIGNOLO, Walter D. A colonialidade de cabo a rabo: o hemisfério ocidental no horizonte conceitual da modernidade. In: Edgardo Lander (org). A colonialidade do saber: eurocentrismo e ciências sociais. Perspectivas latinoamericanas. Coleccin Sur Sur, CLACSO, Ciudad Autnoma de Buenos Aires, Argentina. Setembro 2005. Disponível em: http://bibliotecavirtual.clacso.org.ar/. Acessado em 21 de novembro de 2017.

MIGNOLO, Walter D. Desobediência epistêmica: a opção descolonial e o significado de identidade em política. Cadernos de Letras da UFF - Dossiê: Literatura, língua e identidade, n. 34, p. 287-324, 2008.

MONTEIRO, B. A. P.; DUTRA, D. S. A.; CASSIANI, S. ; SANCHEZ, C. ; OLIVEIRA, R. D. V. L. . Decolonialidades na Educação em Ciências (Coleção culturas, direitos humanos e diversidades na educação em ciências). 1. ed. São Paulo: Livraria da Física, 2019. 395p MOODIE, N. Learning about knowledge: threshold concepts for Indigenous studies in education. The Australian Educational Researcher, v. 46, n. 5, p. 735-749, nov. 2019.

NAZARENO, E.; MAGALHÃES, S. M. DE; FREITAS, M. T. U. Interculturalidade Crítica, Transdisciplinaridade e Decolonialidade na Formação de Professores Indígenas do Povo Berò Biawa Mahadu/Javaé: Análise de Práticas Pedagógicas Contextualizadas em um Curso de Educação Intercultural Indígena. Fronteiras: Journal of Social, Technological and Environmental Science, v. 8, n. 3, p. 490-508, 1 set. 2019. 
OLIVEIRA, L. F. DE; CANDAU, V. M. F. Pedagogia decolonial e educação antirracista e intercultural no Brasil. Educação em Revista, v. 26, n. 1, p. 15-40, abr. 2010.

PAIM, E. A.; PINHEIRO, P. M.; DE PAULA, J. B. Educação, relações etnicorraciais e decolonização na práxis de professores/as. Perspectiva, v. 37, n. 2, p. 437-452, 28 jun. 2019.

PATIÑO GÓMEZ, Z. L.; NARANJO VILLA, L.; SERNA FELIPE, M. Perspectiva de género en las carreras de licenciatura en ciencias sociales y geografía en cuatro universidades públicas de Colombia. Perspectiva Geográfica, v. 23, n. 2, 7 set. 2018.

PAVAN, R.; PANIAGO, M. C. L.; BACKES, J. L. Action Research and intercultural dialogue: An experience with Brazilian Indians. International Journal of Action Research, v. 11, n. 3, p. 339, 2015.

QUIJANO, Anibal. Colonialidade do poder e classificação social. In.: SANTOS, Boaventura de Sousa. MENESES, Maria Paula (Orgs). Epistemologias do Sul. São Paulo. Cortez, 2010.

RAMALLO, F.; GÓMEZ, J. A.; PORTA, L. Pedagogías queer y polifonías del sur: transgresiones y afecciones en la educación en el profesorado. v. 52 p. 1-14, 2018.

Disponível

em:

https://www.researchgate.net/publication/333708556_Pedagogias_queer_e_polifon ias_do_sul_transgressoes_e_afeccoes_na_educacao_nos_professores

RAMOS, Altina. FARIA, Paulo M. Faria, Ádila. Revisão sistemática de literatura: contributo para a inovação na investigação em Ciências da Educação. Rev. Diálogo Educ., Curitiba, v. 14, n. 41, p. 17-36, jan./abr. 2014

ROCHA, A. F. C. DA. Processos e práticas decoloniais na formação de professores. RELACult - Revista Latino-Americana de Estudos em Cultura e Sociedade, v. 3, n. 3, 31 dez. 2017.

SANTOS, Boaventura de Sousa. Do Pós-Moderno ao Pós-Colonial e para além de um e outro. In.: Conferência de Abertura do VIII Congresso Luso-Afro-Brasileiro de Ciências Sociais. 16 a 18 de setembro. Coimbra. 2004. Anais ... Coimbra, 2004

SANTOS, Boaventura de Sousa. MENESES, Maria Paula (Orgs). Epistemologias do Sul. São Paulo. Cortez, 2010.

SPRECHER, K. Preparing Teacher-Researchers for Local-Global, Multicultural Classrooms: Prospects for Postcritical and Feminist Qualitative Methodologies. Taboo. The Journal of Culture and Education, v. 13 n.2. 2019. Disponível em: https://doi.org/10.31390/taboo.13.2.06.

WALSH, Catherine. Interculturalidade crítica e pedagogia decolonial: in-surgir, reexistir e re-viver. In. CANDAU, Vera Maria (Org.). Educação intercultural na América 
Latina: entre concepções, tensões e propostas. Rio de Janeiro: 7 Letras, 2009. p. 1243.

WALSH, Catherine. Pensamiento crítico y matriz (de)colonial. Reflexiones latinoamericanas. Quito: Ediciones Abya-yala, 2005. p. 13-35.

WALSH, Catherine. Notas pedagógicas desde las grietas decoloniales. In: Clivajes. Revista de Ciencias Sociales. Año II, n. 4, julio-diciembre 2015.

WALSH, Catherine. Pedagogías Decoloniales. Práticas Insurgentes de resistir, (re)existir e (re)vivir. Quito: Editora Abya-Yala, 2017 Serie Pensamiento Decolonial

ZEICHNER, K. Preparing Teachers as Democratic Professionals. Action in Teacher Education, v. 42 n. 1, p. 38-48, 2019. Disponível em: https://doi.org/10.1080/01626620.2019.1700847. 